\title{
Brief Assessment of Stock of Mud Crabs Scylla spp. in Matang Mangrove Forest, Malaysia and Proposal for Resources Management
}

\author{
Takeharu KOSUGE* \\ Ishigaki Tropical Station, Seikai National Fisheries Research Institute \\ (148-446 Fukai-ota, Ishigaki, Okinawa, 907-0451 Japan)
}

\begin{abstract}
Current status of the stock of mud crabs was examined in December 1997 in the Matang Mangrove Forest, Malaysia. Scylla serrata accounted for $63 \%$ of the crab stocks and S. olivacea for $37 \%$. According to their size, $80 \%$ of the mud crabs were estimated to be immature. Reduction in the size of the mud crabs was likely to be due to overfishing. Zoning for different levels of fishing in Matang was proposed as a practical measure for mud crab stock management.
\end{abstract}

Discipline: Fisheries

Additional key words: Scylla serrata, Scylla olivacea, stock management

\section{Introduction}

The mud crabs (Scylla spp.) which are important fisheries resources in mangrove environments have been collected extensively in part of their distribution range in Asian-Pacific coastal waters. Since mud crabs became important as exportable fisheries resources, overfishing has occurred more severely in some countries. As a result of overfishing of local populations, both the size and number of mud crabs have decreased. Aquaculture, fatting and sea farming are now conducted in Asian countries to supplement the reduced stock of mud crabs ${ }^{1,7}$.

In the Matang Mangrove Forest Reserve in Perak, Malaysia, the mud crabs are often harvested. A shortterm research project using baited traps was conducted to determine the current status of stocks of mud crabs in Matang.

Ecological studies on population dynamics of different species had been hindered by problems related to the taxonomy of the mud crabs, as several species often occur in the same estuary. Estampador ${ }^{2)}$ demonstrated that mud crabs in the Philippines consisted of 3 species and identified one new sub-species distinguishable by its coloration and morphology. This classification of the mud crabs into 4 taxa, was supported by research in other Asian regions (e. g. Vietnam $\left.{ }^{6}\right)$. However, the status of each taxon (species or subspecies) had not been completely clarified, and confusion about the use of names has tended to persist in many ecological studies.

Recently, problems related to the taxonomy of the genus Scylla have been solved and the nomenclature proposed by Keenan et al. ${ }^{3)}$ was eventually adopted. These authors determined the neotype specimen of Scylla serrata (Forskål), and concluded that all the other 3 species, i.e. S. tranquebarica (Fabricius), S. olivacea (Herbst), and $S$. paramamosain Estampador, are valid and distinct species based on both morphometric and genetic characters. In field identification, the number and form of spines on the outer surface of the carpus of chelipeds, and shape of the frontal lobe exhibit distinctive morphological differences (see the key and Table 5 in Keenan et al. ${ }^{3)}$ ). Although some individuals display intermediate characters across 2 species, the keys developed by Keenan et al. ${ }^{3)}$ can be used in most cases as a practical guide to identify adult mud crabs.

Specimens collected for the present studies were preserved and identified based on the new keys of Keenan et $\mathrm{al}^{3}{ }^{3}$, and thus the present paper is one of the earliest studies on mud crabs using the correct nomenclature.

This study was supported fully by a grant-in-aid for the Research Project on "Productivity and Sustainable Utilization of Brackish Water Mangrove Ecosystems" from Japan International Research Center for Agricultural Sciences. Contribution No. 605 from Seikai National Fisheries Research Institute.

*Corresponding author: fax +81-9808-8-2573, e-mail kosuge@snf-its.affrc.go.jp

Received 5 June 2000, accepted 27 July 2000. 


\section{Methods}

To determine the distribution of the mud crabs along a river, 6 stations were set up along the Sungai (=river) Sangga Besar located in the Matang Mangrove Forest Reserve (Fig. 1). Stations A to F in the present study correspond to Stations 2-7 set up by Tanaka to study the chemical and physical characteristics of the river water (Tanaka et al. $\left.{ }^{8}\right)$, Stations A-E consisted of brackish waters $(0.05-0.27 \%$ in salinity) and Station F of completely fresh water.

Basket-shaped baited traps (or pots) similar to those used by the local fishermen in Matang were employed to catch crabs for the studies. The bottom of the trap is oval $(60 \mathrm{~cm} \times 45 \mathrm{~cm})$ and the height is $32 \mathrm{~cm}$. Size of the mesh covering the trap is $2 \mathrm{~cm}$, and the trap entrance is about 11 $\mathrm{cm}$ wide. Heads of the cat fish Arius spp. were used as the bait based on the method applied by local fishermen. About 20 traps were set at each of the stations in the water near roots of mangroves, and were collected after $2 \mathrm{~h}$. All the trapped animals were examined. Captured mud crabs were identified, the maximum carapace width $(\mathrm{CW})$ was measured using calipers and the sex was recorded. To evaluate the relative abundance of mud crabs at each station, catch per unit effort was calculated as the number of captured crabs divided by the number of traps set for $2 \mathrm{~h}$. Traps which were lost or were not set properly were omitted from the analyses. All the trappings were performed during the daytime from December 16 to 20, 1997.

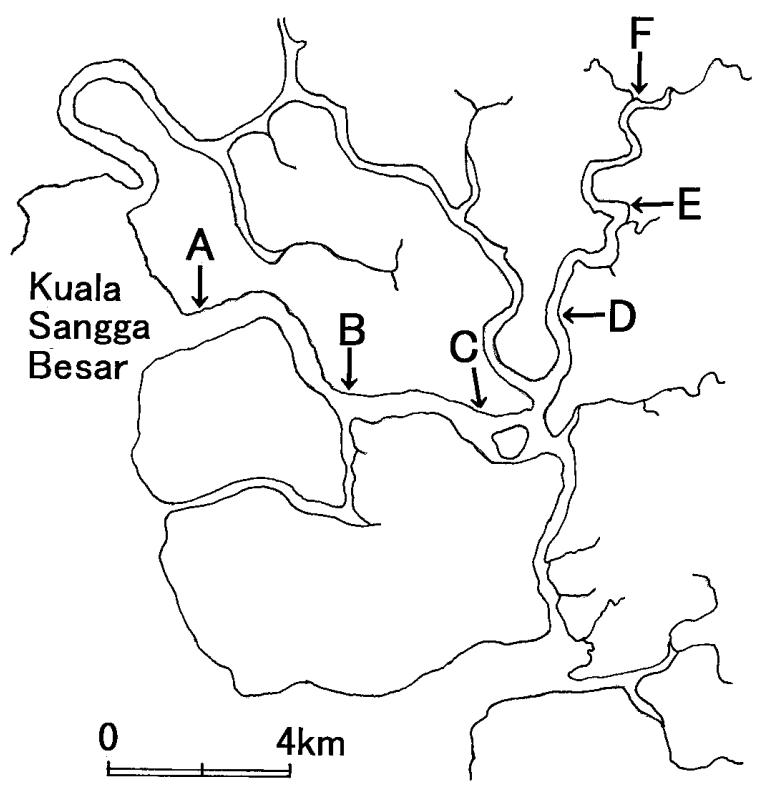

Fig. 1. Map of Sangga Besar River in the Matang Mangrove Forest Reserve showing the 6 study stations

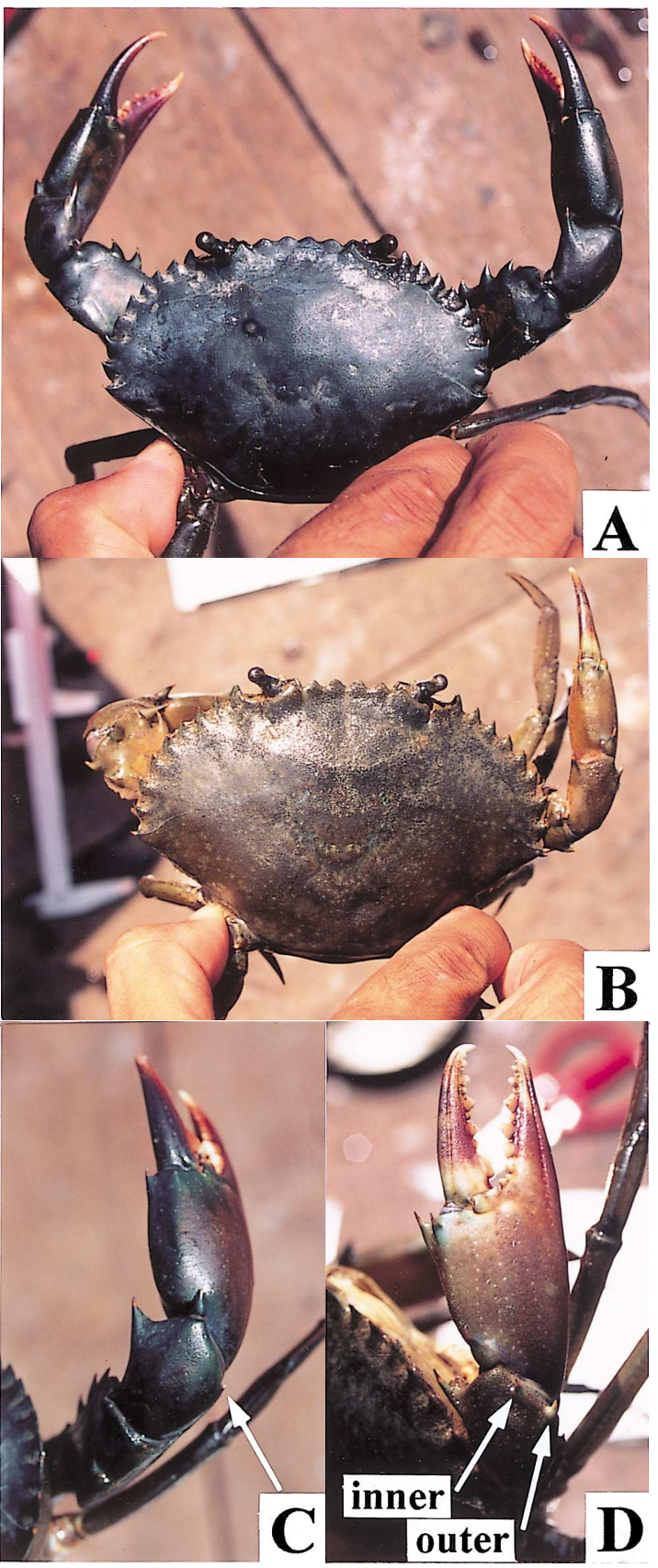

Fig. 2. Two species of mud crabs in Matang, Scylla olivacea $(\mathrm{A}, \mathrm{C})$ and $S$. serrata $(\mathrm{B}, \mathrm{D})$

Note the difference in the shape of the frontal lobe spines: blunt point in $S$. serrata (B) but rounded in S. olivacea (A). Carpus spines of cheliped are both obvious in $S$. serrata (D) whereas the inner one is absent and the outer one is reduced in S. olivacea (C). 


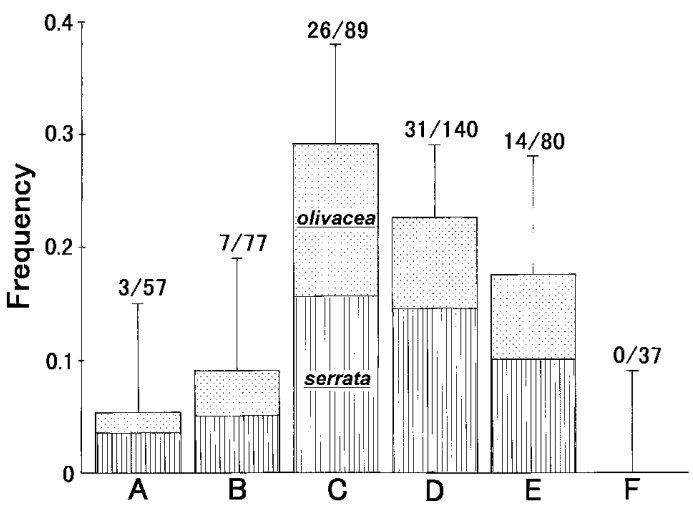

Fig. 3. Relative abundance of the mud crabs Scylla olivacea and $S$. serrata at 6 stations A-F in the Sangga Besar River

The figures above the bars indicate the number of mud crabs per number of traps set for $2 \mathrm{~h}$. Vertical bars indicate $95 \%$ confidence limit.

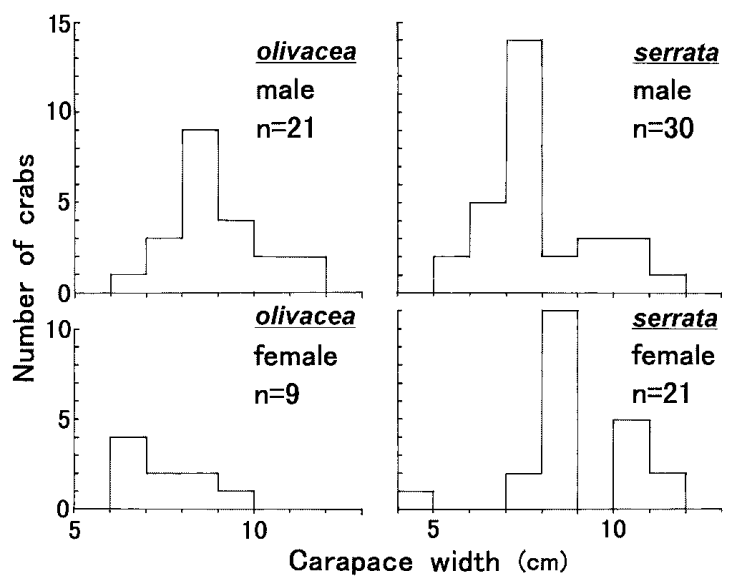

Fig. 4. Size frequency distribution of each sex and species of mud crab, Scylla olivacea and $S$. serrata captured in the Sangga Besar River

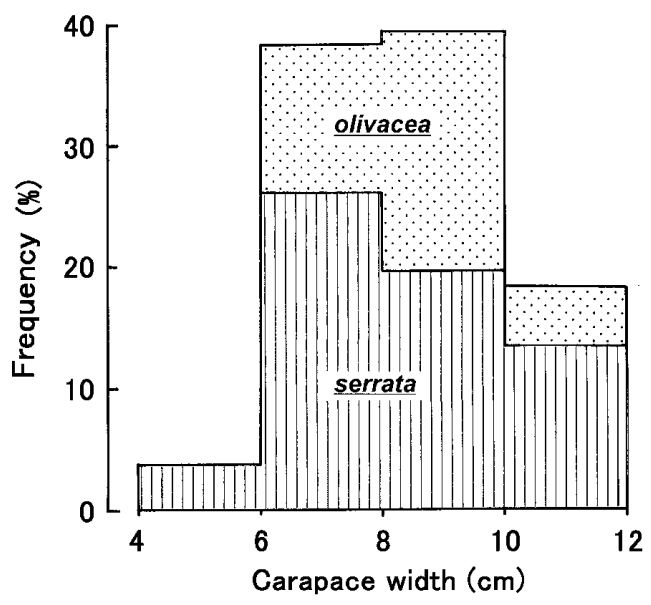

Fig. 5. Size frequency distribution of Scylla olivacea and $S$. serrata in the Sangga Besar River

\section{Results}

All the collected mud crabs were identified as either Scylla olivacea or S. serrata (Fig. 2). Shape of spines on the front, number of spines on the carpus of chelipeds and color patterns corresponded well to the identification keys of Keenan et $\mathrm{al}^{3)}$. In total, 81 mud crabs were trapped, of which 51 belonged to $S$. serrata $(63 \%)$ and 30 to $S$. olivacea (37\%). Thus, $S$. serrata was the most abundant species of mud crabs in Matang, while S. olivacea was commonly distributed but less abundant.

Relative abundance of mud crabs varied along the river (Fig. 3). Some mud crabs were collected from Stations $\mathrm{A}$ to $\mathrm{E}$ but no crabs were trapped in station $\mathrm{F}$, located in the upper stream. Mud crabs were most abundant at station $\mathrm{C}$, with an average of 3 crabs per 10 traps. Upstream of Station C (Stations D and E), the catch was more abundant than at stations closer to the river mouth (Stations A and B). Both species of mud crabs occurred at every station from $A$ to $E$, and the proportion of each species trapped did not vary among the stations.

Size of the mud crabs based on CW measurement ranged from 4-12 cm (Fig. 4). In the males of S. olivacea, a CW of 8-9 cm corresponded to the collected mode, and in all the females, the $\mathrm{CW}$ was below $10 \mathrm{~cm}$. In $S$. serrata, males with a $\mathrm{CW}$ of $7-8 \mathrm{~cm}$ and females with a $\mathrm{CW}$ of $8-9 \mathrm{~cm}$ were most common. The size distribution of all the collected mud crabs showed that nearly $80 \%$ of the mud crabs in Matang were small crabs (CW: 6-10 cm) (Fig. 5).

\section{Discussion}

In the present studies, 2 of the 4 species of Scylla spp. were commonly observed in Matang, with Scylla serrata being the major species and $S$. olivacea being also an important component of mud crab stocks in Matang. Other species, S. tranquebarica and paramamosain, may inhabit this area but were relatively less important in the mud crab stocks there. Distribution of the 2 mud crabs along the Sangga Besar River completely overlapped and no habitat segregation was recognized.

Size of mature mud crabs in Matang, based on CW measurement was $10 \mathrm{~cm}$ for the males and $10-11.4 \mathrm{~cm}$ for the females ${ }^{4}$. In Phuket, Thailand, about $600 \mathrm{~km}$ north of Matang, mature female mud crabs showed a CW of $11 \mathrm{~cm}^{5}$. Although in these previous studies several species of mud crabs were combined, the values of $\mathrm{CW}$ at maturity are useful parameters to estimate the proportion of mature individuals in crab populations in Matang. In the present study, all the females of $S$. olivacea (9/9) and $67 \%(14 / 21)$ of the females of $S$. serrata were immature. 
For the males, $81 \%(17 / 21)$ of $S$. olivacea and $87 \%(26 / 30)$ of $S$. serrata were immature $(C W<10 \mathrm{~cm})$. Thus most of the $S$. olivacea and $S$. serrata in Matang were immature. This reduction in size of both species of mud crab populations in Matang is likely to be associated with overfishing.

Certain guidelines are recommended to preserve the mud crab stock in Matang. A number of methods to control the catch will be considered. Restrictions on the size and sex of crabs caught, the number of traps, period of fishing are necessary. The legal control of these restrictions on fishing will be difficult to implement in Matang. Most fishermen involved in mud crab fishing in Matang are poor, as fishing for mud crabs requires a minimum equipment, i.e. a small boat with a small engine and traps. Thus the initial cost for mud crab fishing is estimated to be lower than that for other types of fishing, e. g. prawns or cockle fishing. If such restrictions were to be implemented, alternative sources of income for these fishermen should be considered.

Another anticipated problem is the demand for small crabs by consumers because of their low price. In the market in Taipin, the closest town to Matang, mud crabs from Matang mangroves are sold in 4 size classes; large $(>10 \mathrm{~cm} \mathrm{CW})$, middle $(9-11 \mathrm{~cm})$, small $(8.5-10 \mathrm{~cm})$ and very small $(7.5-10 \mathrm{~cm})$. The price of the crabs of each class is $10,8,7$ and 5 ringgit per kg, respectively. All the mud crabs, even the small ones, sold well and a total of approximately $20 \mathrm{~kg}$ crabs were bought within $3 \mathrm{~h}$ in the morning (Kosuge, personal observation). Thus, the demand for small crabs in the market suggests that local fishermen would be reluctant to release them after capture.

Despite all these problems, it might still be important to consider the application of some guidelines for mud crab fishing in Matang. In Matang, the mangrove environment and habitat are sound because logging of mangroves has been well managed. This environment is suitable for the maintenance of mud crab populations. In many other regions, the stock level of mud crabs has been reduced with the destruction of the mangrove habitat. Thus it is not possible to separate the direct effects of fishing, from the indirect effects of habitat destruction on the mud crab populations. As the mangrove ecosystem is sound in Matang, this habitat can sustain a large population of mud crabs by providing a sufficient amount of food and adequate shelter. Therefore, rates of recovery in the mud crab stock could be high after fishing restrictions are imposed in Matang.
One practical measure for mud crab fishing management is the development of zoning for different levels of fishing. Matang Mangrove Forest Reserve covers an area of over 40,000 ha and is therefore large enough to be divided into several zones with different levels of fishing of mud crab stocks. For example, Matang could be divided into 4 or 5 zones among which trapping would be completely prohibited in one zone. The process of stock recovery could be monitored in this area. Other areas could be utilized in rotation every one or two years. The management plan should be determined by examining the biological data obtained from the entire area in collaboration with the fishermen. By monitoring the recovery process, effects of fishing restrictions could be separated from other indirect effects and basic information for the management of mud crab resources could be provided.

\section{References}

1) Cholik, F. \& Hanafi, A. (1992): A review of the status of the mud crab (Scylla sp.) fishery and culture in Indonesia. In The mud crab, report on the seminar convened in Surat Thani, Thailand, November 5-8, 1991. ed. Angell, C. A., Bay of Bengal Programme, Madras, India, 13-27.

2) Estampador, E. P. (1949): Studies on Scylla (Crustacea: Portunidae). I. Revision of the genus. Philipp. J. Sci. 78(1), 95-108, pls. 1-3.

3) Keenan, C., Davie, P. J. F. \& Mann, D. L. (1998): A revision of the genus Scylla De Haan, 1833 (Crustacea: Decapoda: Brachyura: Portunidae). Raffles Bull. Zool. 46(1), 217-245.

4) Ong, K. S. (1977): Observations on the post-larval life history of Scylla serrata (Forskål), reared in the laboratory. Malay. Agric. J. 45, 429-443.

5) Poovachiranon, S. (1992): Biological studies of the mud crab Scylla serrata (Forskål) of the mangrove ecosystem in the Andaman Sea. In The mud crab, report on the seminar convened in Surat Thani, Thailand, November 5-8, 1991. ed. Angell, C. A., Bay of Bengal Programme, Madras, India, 49-57.

6) Serène, R. (1952): Les especes du genre Scylla à Nhatrang (Viet-Nam). In Proc. Indo-Pacif. Fish. Counc. 3rd Meet., Madras 1951 Sect. II, Indo-Pacific Fish. Counc., Madras, India, 133-137, fig. 1, pls. 1-2.

7) Sivasubramaniam, K. \& Angell, C. (1992): A review of the culture, marketing and resources of the mud crab (Scylla serrata) in the Bay of Bengal region. In The mud crab, report on the seminar convened in Surat Thani, Thailand, November 5-8, 1991. ed. Angell, C. A., Bay of Bengal Programme, Madras, India, 5-12.

8) Tanaka, K., Sugahara, K., Ohwaki, Y. \& Choo, P.-S. (1998): C, N, P composition of suspended matter in Matang Mangrove Estuary, Malaysia. JARQ 32, 153158. 